\title{
NEUROPATHOLOGICAL CHANGES IN THE BRAIN OF PIGS WITH ACUTE LIVER FAILURE
}

\author{
Rune Gangsøy Kristiansen ${ }^{1}$, Sigurd Lindal2, Kate Myreng², Arthur Revhaug², Lars \\ Marius Ytreb $\emptyset^{1} \&$ Christopher F. Rose ${ }^{4}$
}

\begin{abstract}
${ }^{1}$ Department of Anesthesiology, University Hospital of North Norway and University of Troms $\emptyset$, Sykehusveien, Tromsø, Norway 2Department of Pathology, University Hospital of North Norway and University of Tromsø, Troms $\varnothing$, Norway ${ }^{3}$ Department of Digestive Surgery, University Hospital of North Norway and University of Troms $\varnothing$, Troms $\emptyset$, Norway ${ }^{4}$ Neuroscience Research Unit, Hôpital Saint-Luc (CRCHUM), Université of Montréal, Montreal, Québec, Canada Correspondence: Rune Gangsøy Kristiansen MD, PhD student, Department of Anesthesiology, University Hospital of North Norway and University of Tromsø, N-9038 Tromsø, Norway. +47 95929438. +47 77626192.
\end{abstract} rune ga kri@hotmail.com

\section{ABSTRACT}

Objective. Cerebral edema is a serious complication of acute liver failure (ALF), which may lead to intracranial hypertension and death. An accepted tenet has been that the blood-brain barrier is intact and that brain edema is primarily caused by a cytotoxic etiology due to hyperammonemia. However, the neuropathological changes in ALF have been poorly studied. Using a well characterized porcine model we aimed to investigate ultrastructural changes in the brain from pigs suffering from ALF. Materials and methods. Sixteen female Norwegian Landrace pigs weighing 27-35 kg were randomised into two groups: ALF $(n=8)$ and sham operated controls $(n=8)$. ALF was induced with an end-to-side portacaval shunt followed by ligation of the hepatic arteries. Biopsies were harvested from three different areas of the brain (frontal lobe, cerebellum, and brain stem) following eight hours of ALF and analyzed using electron microscopy. Results. Profound perivascular and interstitial edema were found in all three areas. Disruption of pericytic and astrocytic processes were seen, reflecting breakdown/lesion of the blood-brain barrier in animals suffering from ALF. Furthermore, neurons and axons were edematous and surrounded by vesicles. Severe damage to Purkinje neuron (necrosis) and damaged myelin were seen in the cerebellum and brain stem, respectively. Biopsies from sham operated animals were normal. Conclusions. Our data support the concept that vasogenic brain edema plays an important role in the development of intracranial hypertension in pigs with ALF.

Keywords: Acute liver failure, ammonia, blood-brain-barrier, cerebral edema, hepatic encephalopathy

\section{INTRODUCTION}

Cerebral edema is a serious complication of acute liver failure (ALF), which may lead to intracranial hypertension and death. The exact pathophysiological mechanisms responsible for the development of intracranial hypertension are unresolved however several lines of investigation suggest hyperammonemia is central to its pathogenesis [1-3]. Brain edema has been demonstrated to be closely linked with intracranial hypertension since an increase in brain water tissue has been observed in both patients with and animal models of ALF [4-6].

To date, only one human study has been published describing the neuropathological patterns associated with ALF. In this post mortem electron microscopic study, cerebral edema was illustrated in the frontal cortex of all patients who

The final publication is available at http://dx.doi.org/10.3109/00365521003675047 
died from brain stem herniation due to acetaminophen-induced ALF. Cerebral edema was depicted as mostly due to cytotoxic mechanisms and to a lesser extent vasogenic mechanisms in association with alterations in the permeability of the blood-brain barrier (BBB) [7]. Several animal studies over the last 30 years have demonstrated increased permeability of many substances across the BBB however the integrity of the BBB was not described $[8,9]$. Therefore, a study investigating the ultrastructural changes in the brain in relation to increased ICP in an animal model of ALF is warranted.

Recent publications have demonstrated the importance of brain white matter changes (volume, biochemically, physiologically) in association with the onset of hepatic encephalopathy (HE) in patients with chronic liver disease $[10,11]$. Furthermore, we have previously demonstrated white matter as a more amenable area to treatment and possibly a new therapeutic target [12]. Studies are lacking describing the differentiation between ultrastructural changes in white versus gray matter in association with increased ICP in ALF.

We have previously described a porcine model of ALF, induced by hepatic devascularization, which is associated with typical clinical and biochemical features of ALF including acute hyperammonemia, increased brain water and intracranial hypertension [12-17]. The aim of the present study was to use this large animal model to examine ultrastructural changes in the frontal lobe, cerebellum and brain stem in pigs with ALF.

\section{METHODS}

\section{Study design}

The study was performed in the Surgical Research Laboratory at the University of Tromsø, Norway and was approved by the Norwegian Experimental Animal Board. Sixteen female pigs weighing 27-35 kg were randomised using the sealed envelope system into two groups: (i) ALF ( $n=8)$; (ii) Sham operated control $(n=8)$.

Two pigs (one ALF and one sham) were excluded due to technical errors. Accordingly, data from 14 pigs were thus included in the present study.

\section{Animal preparation}

The pigs were kept in the animal department for at least two days before the experiments. Details regarding the animal room facilities, anesthesia and surgical preparation have previously been reported [13,14]. Briefly, the animals were fasted overnight, but with free access to water. They were premedicated with an intramuscular injection of $20 \mathrm{mg} / \mathrm{kg}$ ketamine (Ketalar, Pfizer, Oslo, Norway) and $1 \mathrm{mg}$ atropine (Atropin, Nycomed Pharma, Oslo, Norway). Anesthesia was induced with an intravenous bolus of $10 \mathrm{mg} / \mathrm{kg}$ pentobarbital (Pentobarbital, Nycomed Pharma, Oslo, Norway) and $10 \mu \mathrm{g} / \mathrm{kg}$ fentanyl (Leptanal, Janssen Pharmaceutica, Beerse, Belgium) and maintained during surgery with a central venous infusion of $4 \mathrm{mg} / \mathrm{kg} / \mathrm{h}$ pentobarbital, $0.02 \mathrm{mg} / \mathrm{kg} / \mathrm{h}$ fentanyl, and $0.3 \mathrm{mg} / \mathrm{kg} / \mathrm{h}$ midazolam (Dormicum; Roche, Basel, Switzerland). The pigs underwent a tracheotomy, were incubated and ventilated $\left(\mathrm{FiO}_{2}=0.5\right)$ on a volume-controlled ventilator (Servo 900, Elema-Schönander, Stockholm, Sweden). Tidal volume was adjusted by means of repeated arterial blood gas analyses to maintain $\mathrm{PaCO}_{2}$ between 4.5 and $5.0 \mathrm{kPa}$ during surgery. Ventilation was not altered after $t=0$. Core body temperature was maintained normothermic at 38.5 $\pm 1^{\circ} \mathrm{C}$ with a heating pad and blankets.

All animals received $500 \mathrm{ml} 0.9 \% \mathrm{NaCl}$ containing $625 \mathrm{mg}$ glucose as a preoperative load. During the experiment, $0.9 \% \mathrm{NaCl}$ was infused at a rate of $3 \mathrm{ml} / \mathrm{kg} / \mathrm{h}$. After ALF induction, $50 \%$ glucose and $20 \%$ human albumin (Octapharm, Hurdal, Norway) were continuously infused at rates of 0.6048 and $0.66 \mathrm{ml} / \mathrm{kg} / \mathrm{h}$, respectively. However, sham-operated animals received only half the amount of glucose $(0.3024 \mathrm{ml} / \mathrm{kg} / \mathrm{h})$ in order to render the glucose levels comparable between the groups.

The final publication is available at http://dx.doi.org/10.3109/00365521003675047 
Anesthesia was stopped after the liver was devascularised. If the degree of sedation became insufficient, small doses of fentanyl and midazolam were given as a bolus. Sham operated animals received continuous anesthesia during the experimental period and received equal amounts of intravenous fluids.

ALF was induced with an end-to-side portacaval shunt followed by ligation of the hepatic arteries at time $0 \mathrm{~h}$ and monitored for $8 \mathrm{~h}$. These animals develop hyperammonemia, brain edema and intracranial hypertension. Details of the surgery, including the sham operation procedure have previously been described $[13,14]$.

\section{Positioning of catheters}

A 16G central venous catheter (Secalon T ${ }^{\mathrm{TM}}$, Ohmeda, Swindon, UK) was introduced into the left external jugular vein for administration of drugs and fluids.

\section{Biopsies}

Biopsy specimens $(5 \mathrm{~mm})$ were obtained from three sites of the brain at $t=8 \mathrm{~h}$ :

(1) Transcortical biopsies were examined from the precentral area from the frontal lobe. Microscopy studies were performed in samples obtained from the transition zone between cortex and white matter tissue.

(2) Brain stem biopsies were obtained from the pons region.

(3) Deep cortical biopsies were obtained from the inferior part of the right lobe of the cerebellum.

All biopsies were taken from deeply anesthetized animals in the same order at each experiment. Frontal lobe biopsies were harvested first, then subsequently the cerebellum and pons samples as soon as the brain was dissected free from the cranium. The animals were then subsequently sacrificed with an overdose potassium and pentothal injection.

Biopsies were fixed in McDowells fixative ( $>24 \mathrm{~h}$ ) immediately after harvesting. Post-fixation was performed in $1 \%$ aqueous $\mathrm{OsO}_{4}$. The specimens were dehydrated in series of graded ethanol and thereafter embedded in Epon/aradite.

Semi-thin sections $(2 \mu \mathrm{m})$ of four blocks from each biopsy were sectioned and stained with $1 \%$ toluidine blue. The sections were examined in light microscopy to verify representative material and to select areas for electron microscopic examination.

Ultra-thin sections $(70 \mathrm{~nm})$ from the selected areas were contrasted with $5 \%$ uranylacetat and subsequently with Reynold's lead citrate. The specimens were examined in a JEOL 1010 electron microscope.

\section{Semiquantitative evaluation of ultrastructural changes}

We performed a semiquantitative evaluation of ultrastructural changes of the brain samples. Prior to ultrastructural examination, semi-thin sections for light microscopic examinations were performed and areas for further study by transmission electron microscopy were subsequently defined. The severity of ultrastructural changes was graded in a scoring system described in Tables I-III. All sections were blinded for the investing pathologist. The most pronounced changes in each biopsy specimens were selected for each scoring. From each pig we selected eight micrographs from each region, which were examined and scored.

The final publication is available at http://dx.doi.org/10.3109/00365521003675047 
Kristiansen, R.G. et al., 2010. Neuropathological changes in the brain of pigs with acute liver failure. Scandinavian journal of gastroenterology, 45(7-8), p.935-943.

Table I. Semiquantitative evaluation of ultrastructural changes in the frontal lobe.

\begin{tabular}{lccc}
\hline Variable & SHAM & ALF & $p^{\star}$ \\
\hline Edema $^{\dagger}$ & $1.6 \pm 0.1$ & $3.6 \pm 0.4$ & $<0.001$ \\
Neurons $^{\ddagger}$ & $1.9 \pm 0.2$ & $2.8 \pm 0.1$ & $<0.001$ \\
Astrocytes $^{8}$ & $1.8 \pm 0.2$ & $2.9 \pm 0.1$ & $<0.001$ \\
Oligodendroglia/myelin $^{\dagger}$ & $1.4 \pm 0.2$ & $1.8 \pm 0.2$ & 0.13
\end{tabular}

Mean \pm SEM. Parallel specimens $(n=7)$ from each area were blindly examined.

*Independent $t$-test.

${ }^{\dagger} 0=$ none, $1=$ interstitial, $2=$ perivascular, $3=$ perivascular with vesicles, $4=$ massive perivascular and perineuronal, $5=$ fragmentation of blood-brain barrier.

${ }^{\ddagger} 0=$ none, $1=$ swelling, indentation, $2=$ margination of chromatin, $3=$ clumping, necrosis.

${ }^{8} 0=$ none, $1=$ swelling, $2=$ margination of chromatin, $3=$ necrosis.

${ }^{5} 0=$ none, $1=$ swelling, $2=$ duplication and condensation of chromatin, $3=$ necrosis and degeneration.
Table II. Semiquantitative evaluation of ultrastructural changes in the cerebellum.

\begin{tabular}{lccr}
\hline Variable & SHAM & ALF & \multicolumn{1}{c}{$p^{\star}$} \\
\hline Edema $^{\dagger}$ & $1.4 \pm 0.1$ & $3.3 \pm 0.2$ & $<0.001$ \\
Neurons $^{\ddagger}$ & $2.1 \pm 0.2$ & $2.8 \pm 0.1$ & 0.016 \\
Astrocytes $^{8}$ & $1.2 \pm 0.1$ & $2.3 \pm 0.1$ & $<0.001$ \\
Oligodendroglia/myelin $^{\dagger}$ & $1.2 \pm 0.1$ & $1.9 \pm 0.1$ & $<0.001$ \\
\hline
\end{tabular}

Mean \pm SEM. Parallel specimens $(n=7)$ from each area were blindly examined.

*Independent $t$-test.

${ }^{\dagger} 0=$ none, $1=$ interstitial, 2 = perivascular, $3=$ perivascular with vesicles, $4=$ massive perivascular and perineuronal, $5=$ fragmentation of blood-brain barrier.

${ }^{\ddagger} 0=$ None, $1=$ swelling, indentation, $2=$ margination of chromatin, 3 = clumping, necrosis.

${ }^{8} 0=$ None, $1=$ swelling, $2=$ margination of chromatin, $3=$ necrosis. ${ }^{\circ} 0=$ None, 1 = swelling, 2 = duplication and condensation of chromatin, $3=$ necrosis and degeneration.

Table III. Semiquantitative evaluation of ultrastructural changes in the brain stem.

\begin{tabular}{lccc}
\hline Variable & SHAM & $\mathrm{ALF}$ & $p^{\star}$ \\
\hline Edema $^{\dagger}$ & $1.2 \pm 0.1$ & $2.5 \pm 0.2$ & $<0.001$ \\
Neurons $^{\ddagger}$ & $1.9 \pm 0.1$ & $2.8 \pm 0.1$ & $<0.001$ \\
Astrocytes $^{5}$ & $1.6 \pm 0.2$ & $3.0 \pm 0.0$ & $<0.001$ \\
Oligodendroglia/myelin $^{\uparrow}$ & $1.8 \pm 0.1$ & $2.7 \pm 0.1$ & $<0.001$ \\
\hline
\end{tabular}

Mean \pm SEM. Parallel specimens $(n=7)$ from each area were blindly examined.

*Independent $t$-test.

${ }^{\dagger} 0=$ none, $1=$ interstitial, $2=$ perivascular, $3=$ perivascular with vesicles, $4=$ massive perivascular and perineuronal, $5=$ fragmentation of blood-brain barrier.

${ }^{\ddagger} 0=$ none, $1=$ swelling, indentation, $2=$ margination of chromatin, $3=$ clumping, necrosis.

${ }^{5} 0=$ none, $1=$ swelling, $2=$ margination of chromatin, $3=$ necrosis.

${ }^{\circ} 0=$ None, 1 = swelling. 2 = duplication and condensation of chromatin, $3=$ necrosis and degeneration. 
Kristiansen, R.G. et al., 2010. Neuropathological changes in the brain of pigs with acute liver failure. Scandinavian journal of gastroenterology, 45(7-8), p.935-943.

\section{RESULTS}

\section{Gross description of the brain}

The brains from pigs with ALF were swollen with flattening of the gyri and narrowing of the sulci. No signs of subarachnoid bleeding were seen. The cut surfaces of the brains were wet and shiny with blurred transmission between cortex and white substance. The ventricles were compressed. Brains from sham operated animals appeared normal.

Representative areas were chosen for the electron microscope pictures presented. In pigs with ALF we found gross ultrastructural changes in all regions (frontal lobe, cerebellum and brain stem) examined, while only minor changes were observed in sham operated controls (Figures 1A-3B). Semiquantitative evaluations were performed in all regions of the brain and significant differences were found in degrees of edema, morphology of astrocytes, neurons and oligodendrocytes/myelin in all areas examined, except for oligodendrocytes/myelin in the frontal lobe (Tables I-III).
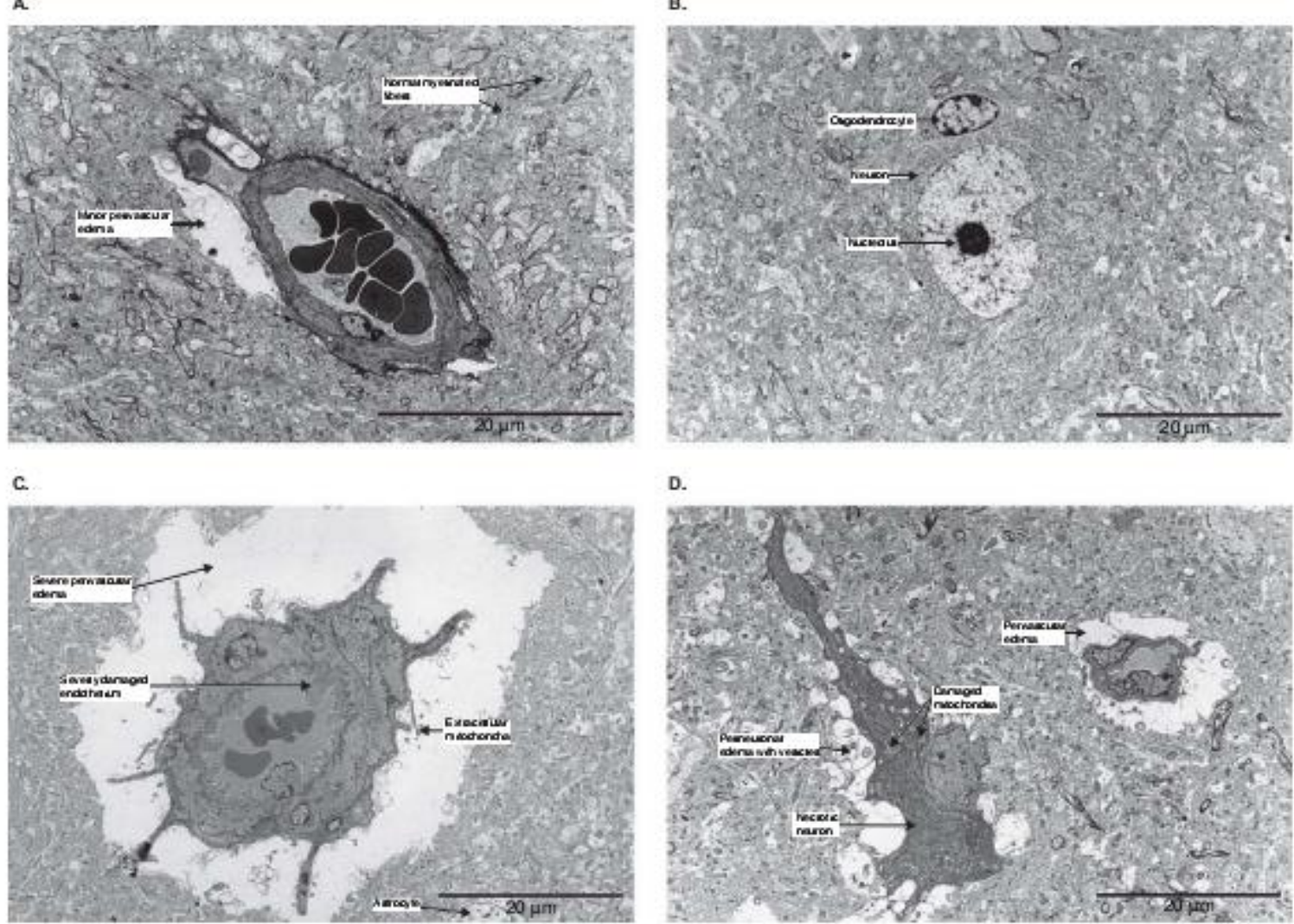

Figure 1. (A) Frontal lobe from a sham operated control pig showing a normal ultrastructural picture except for minor perivascular edema. Normal myelinated fibers can be spotted across the picture. (B) Frontal lobe from a sham operated control pig. Neuron appears normal with distinct nucleolus. Healthy oligodendrocyte appears above. (C) Frontal lobe from a pig with ALF. Severely damaged endothelium can be seen as cytoplasmic papillary projections into the lumen. Severe perivascular edema and cellular debris can be seen. Numerous broken projections are radiating from the vessel wall, ending blindly into the perivascular space. (D) Frontal lobe from a pig with ALF. In the center a dark neuron with shrunken cytoplasm and damaged mitochondria can be seen. Perineuronal vesicles, which probably reflect edema, can be seen. Furthermore, a capillary with perivascular edema with electron dense fragments can be seen. This probably reflects rests of swollen astrocytic processes.

The final publication is available at http://dx.doi.org/10.3109/00365521003675047 
Kristiansen, R.G. et al., 2010. Neuropathological changes in the brain of pigs with acute liver failure. Scandinavian journal of gastroenterology, 45(7-8), p.935-943.
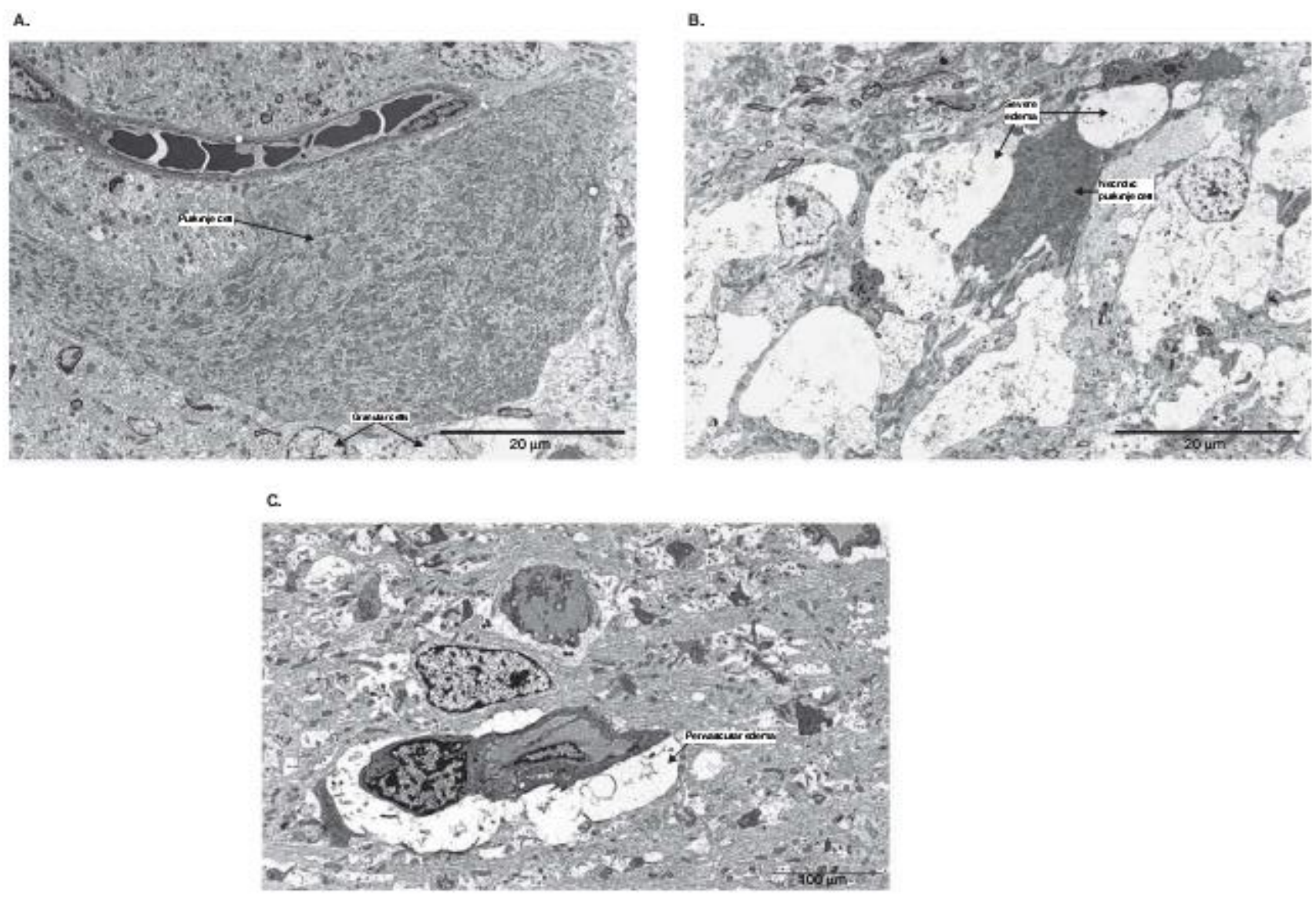

Figure 2. (A) Cerebellum from a sham operated control pig. A normal Purkinje cell and capillary without any signs of perivascular edema. Two granular cells are observed at the bottom of the picture. (B) Cerebellum from a pig with ALF. Focal areas revealing parenchymal cells with severe ultrastructural changes with intracellular edema and broken cell membranes reflecting irreversible changes in granular cells. Shrunken and dark Purkinje cells are observed. (C), Cerebellum from a pig with ALF. This picture shows predominantly a perivascular edema.

\section{Perivascular edema}

Edema, mainly perivascular edema, was seen in biopsies sampled from all regions of the brain in the ALF pigs with minor edema seen in the sham operated controls. We evaluated all samples with a semiquantitative scoring system. The mildest ultrastructural changes of edema in our scoring system (score 1), reflected clear spaces between parenchymal cells and small perivascular clear spaces partially around the capillary (Figure 1A). Moderate edema (score 2) reflected more pronounced perivascular changes with clear spaces surrounding the whole capillary and swelling of the endothelial cells. Advanced perivascular edema (score 3) showed in addition to perivascular white space, ultrastructural changes in the endothelial cells including cytoplasmatic vesicles and vacuoles, margination of the nuclear chromatin, and small gaps in the luminal plasma membrane or projecting blebs into the lumen. The most severe changes which reflect rigorous perivascular edema (score 4), revealed in addition to the above alterations of the endothelial cells with marked intracellular edema, margination and clumping of nuclear chromatin and endothelial cells bulging into and encroaching upon the lumen. The most conspicuous ultrastructural finding in these biopsies were numerous concentric processes radiating from external vascular wall (score 4). These processes ended blindly into disruption of the cytoplasmic membrane with surrounding cellular debris, which are consistent with pericytic processes and remaining astroglial foot processes. The perivascular broken processes together with

The final publication is available at http://dx.doi.org/10.3109/00365521003675047 
Kristiansen, R.G. et al., 2010. Neuropathological changes in the brain of pigs with acute liver failure. Scandinavian journal of gastroenterology, 45(7-8), p.935-943.

massive perivascular edema reflect disruption of the perivascular cytoskeleton structure and thus breakdown of the BBB.

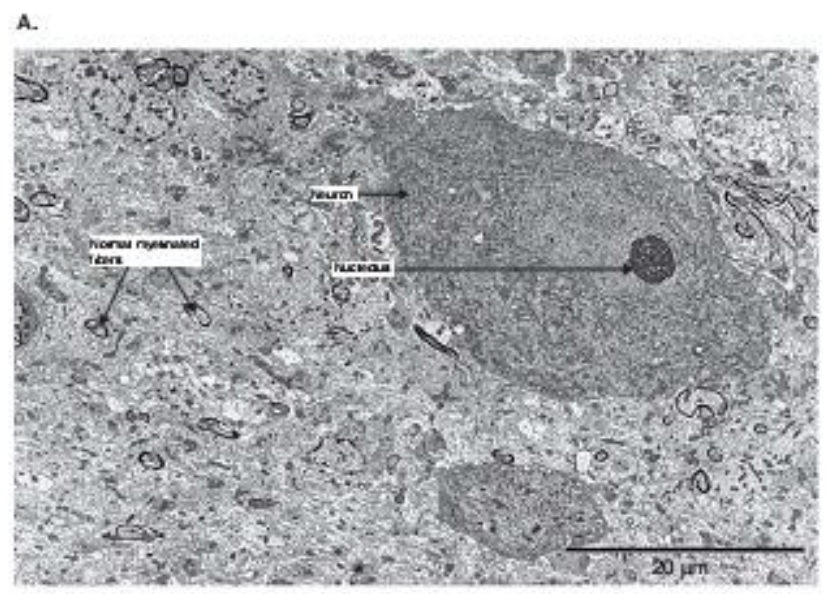

B.

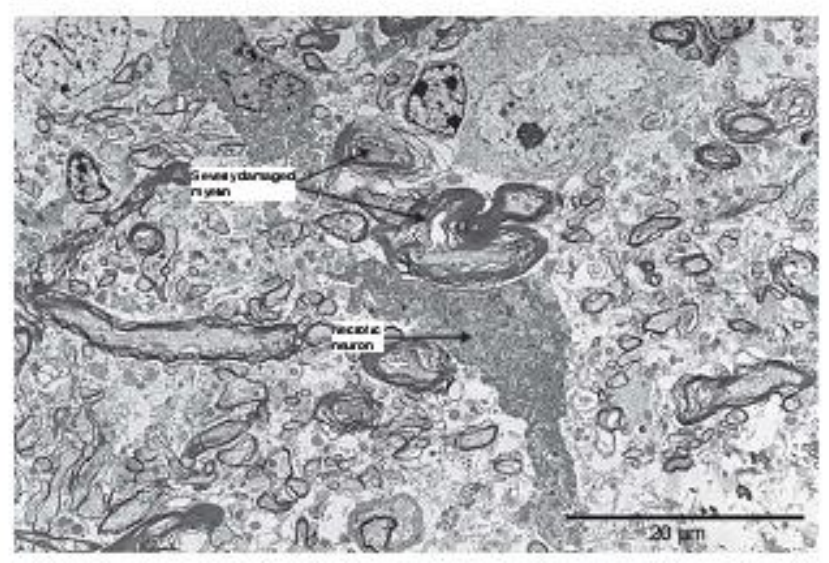

Figure 3. (A) Brain stem from a sham operated pig. Neuron with a distinct nucleolus without any signs of perivascular edema. (B) Brain stem from pig with ALF. Dark parenchymal cells, probably with irreversible damage. Partly swollen and partly condensated myelin processes.

\section{Neurons}

The ultrastructural changes in the neurons of the frontal lobe, the brainstem and the Purkinje cells in the cerebellum, were graded into three different categories according to severity. The mildest were cell swelling with intracellular edema, condensation of cytoplasma and marked nucleolus and indentations of the nuclear membrane (score 1) (Figures 1B, 2A and 3A). Moderate changes in the neurons revealed swelling of the cells with cytoplasmatic vesicles, clumping and margination of nuclear chromatin and increased electron density of the cytoplasma (score 2). Severe ultrastructural changes (score 3) revealed electron dense shrunken neurons, which were surrounded by vesicles. The vesicles contained often cellular debris, reflecting organelles and disruption of the cytoplasmic membrane, suggestive of necrosis (Figures 1D and 2B).

\section{Glia cells}

The severity of ultrastructural changes in astrocytes and oligodendrocytes were divided into three different morphological categories. The mildest changes (score 1) was simple intracellular edema and swelling of the cytoplasma. Moderate changes (score 2) in glia cells were detected when cells showed signs of increased electron

The final publication is available at http://dx.doi.org/10.3109/00365521003675047 
density and condensation of cytoplasma, with marginating and clumping of the nuclear chromatin (Figure 3A). The most severe grade of ultrastructural alteration in glia cells (score 3) were described as further condensation of cytoplasma with shrinking of the cells and cytoplasmic membrane dissolution, suggestive of irreversible changes and necrosis (Figure 3B).

\section{Oligodendrocytes/myelin}

The mildest ultrastructural changes (score 1) were swelling of the myelin sheath (Figure 1A). Moderate changes in the myelin fibers (score 2) were described as swelling and additional blurring with electron dense condensation of the lamina of the myelinated nerve fibers (Figure 3A). The most severe changes in the myelinated fibers (score 3) were detected when the myelin sheath was clearly swollen, irregular in shape with duplicated myelin lamina and electron dense areas with condensation of the lamina (Figure 3B).

\section{Inflammatory cells}

Few inflammatory cells were detected throughout all specimens examined. However, in the ALF group polymorph nuclear granulocytes were found in focal areas where they surrounded areas of necrotic cells (Figure 3A). Macrophages were difficult to identify with the ultrastructural technique applied, but activated platelets were detected within the lumen of small arterioles (Figure 1A).

\section{DISCUSSION}

The present study is the first ultrastructural investigation of the brain in a large animal model of ALF. Following eight hours of liver devascularisation, this porcine model reveals typical clinical and biochemical features of ALF such as hyperammonemia, increased brain edema and intracranial hypertension [12-15], which are considered essential for studying neuropathological changes in the brain in relation to ALF. The major findings in our study were: (1) vasogenic brain edema is an important pathophysiological component associated with intracranial hypertension and (2) evidence of severe brain injury including edema, cellular swelling and necrotic cell death (neurons and astrocytes).

This study is highly relevant for clinical practice as it might change our understanding of the timeframe and development towards BBB breakdown in patients suffering from ALF. Our findings challenge the accepted tenet that BBB is intact in ALF and that brain edema observed is a purely a result of cytotoxic mechanisms [18,19]. In our study, we demonstrate that vasogenic brain edema is an important pathophysiological component in the development of intracranial hypertension in ALF. Our study has recently been supported by Chen and colleagues [20] who demonstrated disruptions of tight junction proteins implicated in the integrity of the BBB in mice with ALF. Kato et al. published the only human study over 15 years ago, looking at ultrastructural changes of the brain in patients who died of ALF [7]. Although they could not find any signs of ruptured BBB, significant dilatations of extracellular spaces were interpreted as evidence of a potential vasogenic component in the pathogenesis of brain edema. Differences in duration of insult and severity of liver failure might explain some of the ultrastructural differences between our present study and that by Kato et al. In their study, arterial ammonia levels were not reported, but all patients had increased ICP (> $30 \mathrm{mmHg}$ ) with clinical signs of cerebral edema (extensor posturing, opisthothonus, and papillary abnormalities) reflecting severe ALF with grade IV HE. Unfortunately the ultrastructural examinations, for ethical reasons were limited to only a tiny piece of frontal cortex obtained at the site of insertion of the extradural ICP catheter [7].

Disruption of the BBB is of specific interest as clinical recommendations advocate the use of hypertonic solutions to treat high ICP in ALF [4]. This treatment concept is based upon the presumption of an intact BBB, which may not be the case in severe ALF with high HE score [7,21]. The present results should therefore lead to a discussion about the

The final publication is available at http://dx.doi.org/10.3109/00365521003675047 
Kristiansen, R.G. et al., 2010. Neuropathological changes in the brain of pigs with acute liver failure. Scandinavian journal of gastroenterology, 45(7-8), p.935-943.

validity of current intensive care treatment protocols and should lead to a review of the current use of hypertonic fluids, which might be ineffective or even hazardous in subgroups of patients with ALF. However, the present investigation was not designed to study reversibility of brain edema in ALF. Accordingly, future studies should focus on the early stages of this disease as one or more interventions (e.g. hypothermia) may change the natural course and prevent the development of intracranial hypertension.

In our present study we analyzed brain tissue from three different regions. Perivascular edema was observed in all regions analyzed with little cytotoxic edema. Morphological changes in neurons, astrocytes and oligodendrocytes were identified as well. This translates into ultrastructural changes found in both white and gray matter. However the brain is not homogeneously affected during ALF since no ultrastructural changes were found with myelin in the frontal lobe as well as with the neurons (Purkinje cells) in the cerebellum.

Evidence from our study demonstrating severe brain damage questions whether HE induced by ALF is purely a metabolic syndrome and reversible. This potentially helps explain the persisting neurological complications in patients following liver transplantation [6,22-24]. Furthermore, even though liver transplantation dramatically improves the clinical neurological status, there is evidence in the literature to suggest that minimal HE may persist due to unknown irreversible changes in the brain $[25,26]$. Therefore full recovery and reversibility of HE following liver transplantation is currently under scrutiny [23].

Additional pathogenic factors such as inflammation have demonstrated to play a role in the exacerbation of ICP in ALF [27], however inflammatory cells (microglia) were not very prominent in the brains of pigs with ALF. This may be obvious since we have previously shown that systemic inflammatory markers are not raised in this model following $6 \mathrm{~h}$ of ALF [12]. Therefore we were able to demonstrate severe ultrastructural changes in the brain without any induction of inflammatory cells. This is clinically relevant as inflammation is believed to play a major role in patients with acute-on-chronic and ALF patients suffering from high grade HE [28,29]. Furthermore, the results of our study suggest inflammation does not play an important role in the development of brain edema and intracranial hypertension in ALF.

Discrepancy in the literature concerning BBB integrity in ALF may be related to studies which measured brain edema and not ICP. It is intracranial hypertension which is a major cause of death in ALF, not brain edema. The former is impossible to occur without the latter, however brain edema can develop without increasing ICP since a non-linear relationship between brain edema and ICP exists. Whether cytotoxic edema precedes vasogenic edema in relation to increased ICP needs to be investigated in the near future. Furthermore, our data demonstrates edema is observed in different areas of the brain, not only one, which may explain an increase in ICP.

In conclusion, ALF causes severe irreversible brain damage and disruption of the BBB. Our data support the concept that vasogenic brain edema plays an important role in the development of intracranial hypertension in pigs with ALF.

\section{ACKNOWLEDGEMENTS}

The authors thank Janne Andreassen, Monica Figenschou, Hege Hagerup, Harry Jensen, and Mehrdad Sobkhez for excellent technical support during the experiments. Funding: This work has been funded by the Norwegian Research Council, Helse Nord (Regional Research Council), University Hospital of North Norway, and University of Tromsø.

Declaration of interest: The authors report no conflicts of interest. The authors alone are responsible for the content and writing of the paper.

The final publication is available at http://dx.doi.org/10.3109/00365521003675047 
Kristiansen, R.G. et al., 2010. Neuropathological changes in the brain of pigs with acute liver failure. Scandinavian journal of gastroenterology, 45(7-8), p.935-943.

\section{REFERENCES}

[1] Clemmesen JO, Larsen FS, Kondrup J, Hansen BA, Ott P. Cerebral herniation in patients with acute liver failure is correlated with arterial ammonia concentration. Hepatology 1999;29:648-53.

[2] Bernal W, Hall C, Karvellas CJ, Auzinger G, Sizer E, Wendon J. Arterial ammonia and clinical risk factors for encephalopathy and intracranial hypertension in acute liver failure. Hepatology 2007;46:1844-52.

[3] Bhatia V, Singh R, Acharya SK. Predictive value of arterial ammonia for complications and outcome in acute liver failure. Gut 2006;55:98-104.

[4] Blei AT. Brain edema in acute liver failure: can it be prevented? Can it be treated? J Hepatol 2007;46:564-9.

[5] Rose C, Michalak A, Pannunzio M, Chatauret N, Rambaldi A, Butterworth RF. Mild hypothermia delays the onset of coma and prevents brain edema and extracellular brain glutamate accumulation in rats with acute liver failure. Hepatology 2000;31:872-7.

[6] Stewart CA, Cerhan J. Hepatic encephalopathy: a dynamic or static condition. Metab Brain Dis 2005;20:193-204.

[7] Kato M, Hughes RD, Keays RT, Williams R. Electron microscopic study of brain capillaries in cerebral edema from fulminant hepatic failure. Hepatology 1992;15:1060-6.

[8] Zaki AE, Ede RJ, Davis M, Williams R. Experimental studies of blood brain barrier permeability in acute hepatic failure. Hepatology 1984;4:359-63.

[9] Livingstone AS, Potvin M, Goresky CA, Finlayson MH, Hinchey EJ. Changes in the blood-brain barrier in hepatic coma after hepatectomy in the rat. Gastroenterology 1977;73:697-704.

[10] Shah NJ, Neeb H, Kircheis G, Engels P, Haussinger D, Zilles K. Quantitative cerebral water content mapping in hepatic encephalopathy. Neuroimage 2008;41:706-17.

[11] Rovira A, Minguez B, Aymerich FX, Jacas C, Huerga E, Cordoba J, Decreased white matter lesion volume and improved cognitive function after liver transplantation. Hepatology 2007;46:1485-90.

[12] Sen S, Rose C, Ytrebo LM, Davies NA, Nedredal GI, Drevland SS, Effect of albumin dialysis on intracranial pressure increase in pigs with acute liver failure: a randomized study. Crit Care Med 2006;34:158-64.

[13] CrossRef, ISI

[14] Ytrebo LM, Nedredal GI, Langbakk B, Revhaug A. An experimental large animal model for the assessment of bioartificial liver support systems in fulminant hepatic failure. Scand J Gastroenterol 2002;37:1077-88.

[15] Ytrebo LM, Ingebrigtsen T, Nedredal GI, Elvenes OP, Korvald C, Romner B, Protein S-100beta: a biochemical marker for increased intracranial pressure in pigs with acute hepatic failure. Scand J Gastroenterol 2000;35:546-51.

[16] Ytrebo LM, Korvald C, Nedredal GI, Elvenes OP, Nielsen Grymyr OJ, Revhaug A. N-acetylcysteine increases cerebral perfusion pressure in pigs with fulminant hepatic failure. Crit Care Med 2001;29:1989-95.

[17] Sen S, Ytrebo LM, Rose C, Fuskevaag OM, Davies NA, Nedredal GI, Albumin dialysis: a new therapeutic strategy for intoxication from protein-bound drugs. Intensive Care Med 2004;30:496-501.

[18] Ytrebo LM, Sen S, Rose C, Davies NA, Nedredal GI, Fuskevaag OM, Systemic and regional hemodynamics in pigs with acute liver failure and the effect of albumin dialysis. Scand J Gastroenterol 2006;41:1350-60.

[19] Chavarria L, Oria M, Romero J, Alonso J, Lope-Piedrafita S, Cordoba J. Diffusion Tensor Imaging Supports the Cytotoxic Origin of Brain Edema in a Rat Model of Acute Liver Failure. Gastroenterology 2009.

[20] Bemeur C, Chastre A, Desjardins P, Butterworth RF. No changes in expression of tight junction proteins or blood-brain barrier permeability in azoxymethane-induced experimental acute liver failure. Neurochem Int 2010;56:205-7.

[21] Chen F, Ohashi N, Li W, Eckman C, Nguyen JH. Disruptions of occludin and claudin-5 in brain endothelial cells in vitro and in brains of mice with acute liver failure. Hepatology 2009;50:1914-23.

[22] Jalan R, Damink SW, Deutz NE, Lee A, Hayes PC. Moderate hypothermia for uncontrolled intracranial hypertension in acute liver failure. Lancet 1999;354:1164-8.

[23] Ferenci P, Lockwood A, Mullen K, Tarter R, Weissenborn K, Blei AT. Hepatic encephalopathy - definition, nomenclature, diagnosis, and quantification: final report of the working party at the 11th World Congresses of Gastroenterology,

Vienna, 1998. Hepatology 2002;35:716-21.

[24] Rose C, Jalan R. Is minimal hepatic encephalopathy completely reversible following liver transplantation? Liver Transpl 2004;10:84-7.

[25] Sotil EU, Gottstein J, Ayala E, Randolph C, Blei AT. Impact of preoperative overt hepatic encephalopathy on neurocognitive function after liver transplantation. Liver Transpl 2009;15:184-92.

The final publication is available at http://dx.doi.org/10.3109/00365521003675047 
Kristiansen, R.G. et al., 2010. Neuropathological changes in the brain of pigs with acute liver failure. Scandinavian journal of gastroenterology, 45(7-8), p.935-943.

[26] Mechtcheriakov S, Graziadei IW, Mattedi M, Bodner T, Kugener A, Hinterhuber HH, Incomplete improvement of visuomotor deficits in patients with minimal hepatic encephalopathy after liver transplantation. Liver Transpl 2004;10:7783.

[27] Wright G, Jalan R. Management of hepatic encephalopathy in patients with cirrhosis. Best Pract Res Clin Gastroenterol 2007;21:95-110.

[28] Rolando N, Wade J, Davalos M, Wendon J, Philpott-Howard J, Williams R. The systemic inflammatory response syndrome in acute liver failure. Hepatology 2000;32:734-9.

[29] Shawcross DL, Wright G, Olde Damink SW, Jalan R. Role of ammonia and inflammation in minimal hepatic encephalopathy. Metab Brain Dis 2007;22:125-38.

[30] Shawcross D, Jalan R. The pathophysiologic basis of hepatic encephalopathy: central role for ammonia and inflammation. Cell Mol Life Sci 2005;62:2295-304.

The final publication is available at http://dx.doi.org/10.3109/00365521003675047 